\title{
AFRICAN AMERICAN 50+ VOTERS' VIEWS ON PRESCRIPTION DRUGS
}

July 2021

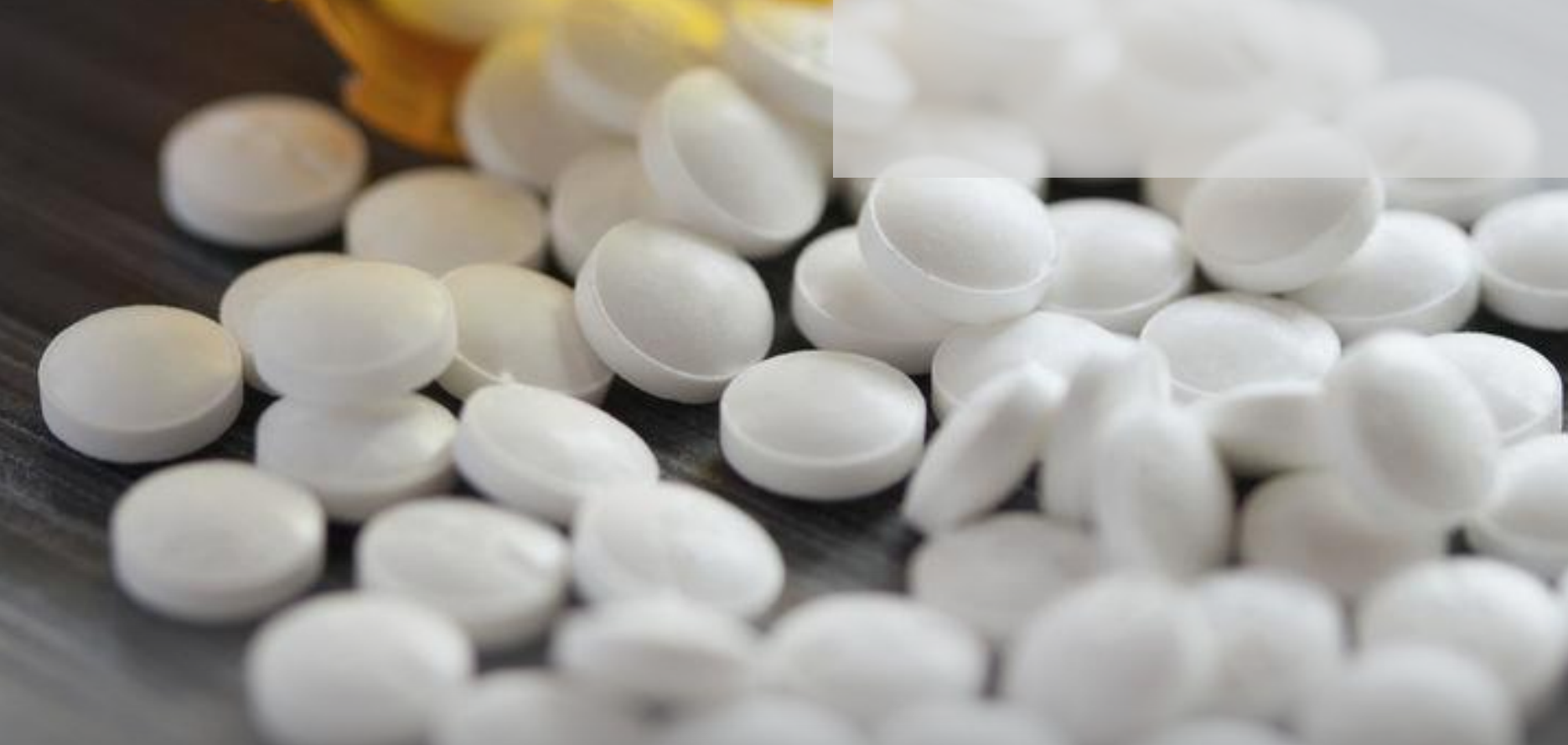




\section{Table of Contents}

Key Findings

3

Prescription Drug Use and Perceptions

5

Policy and Innovation

9

Implications

17

Methodology

19

Contact

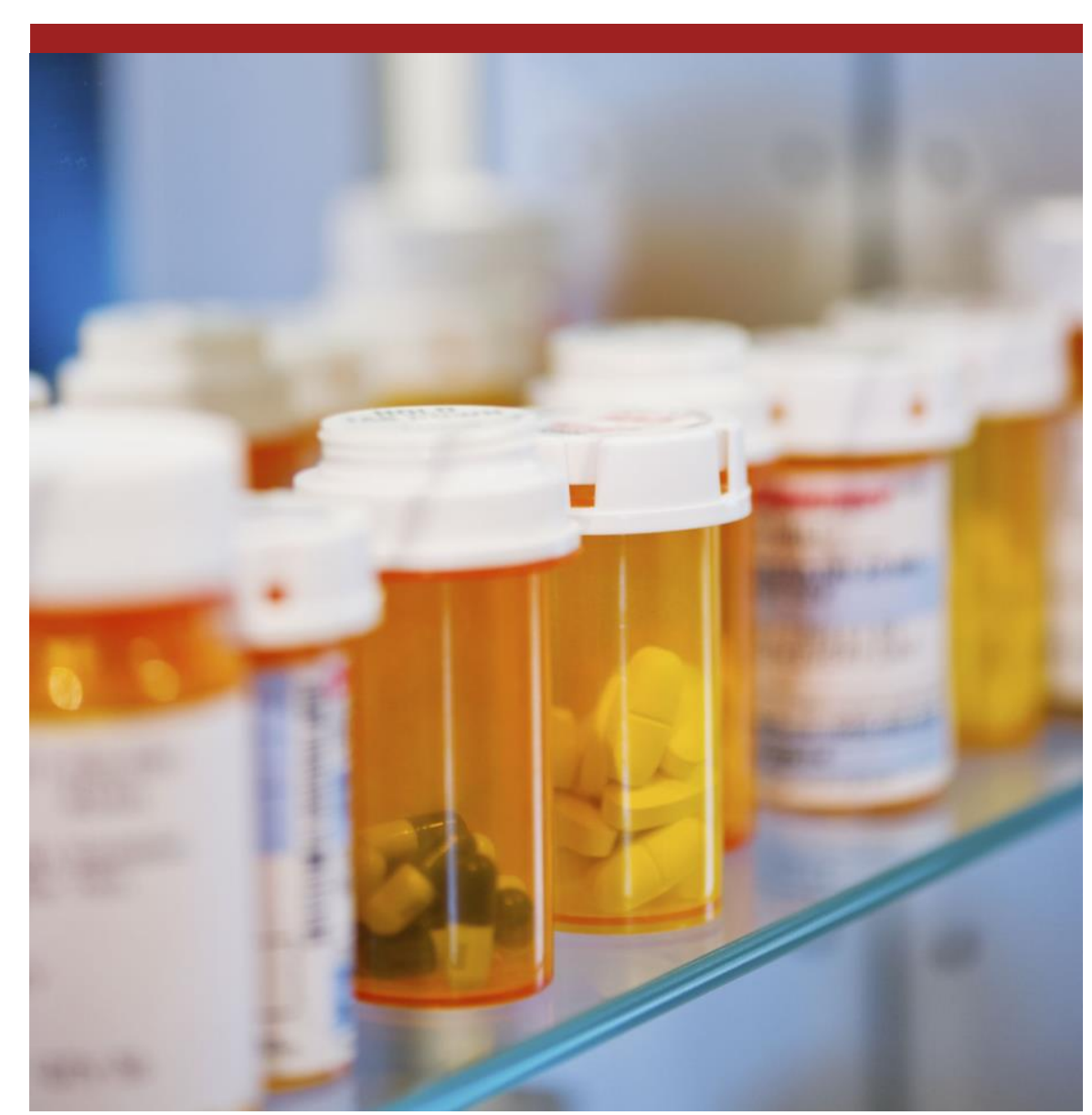




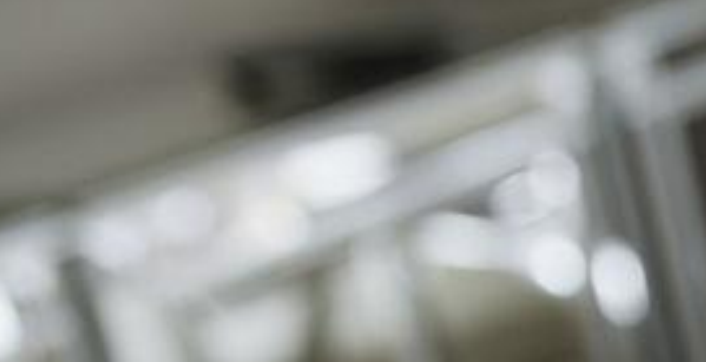

fer
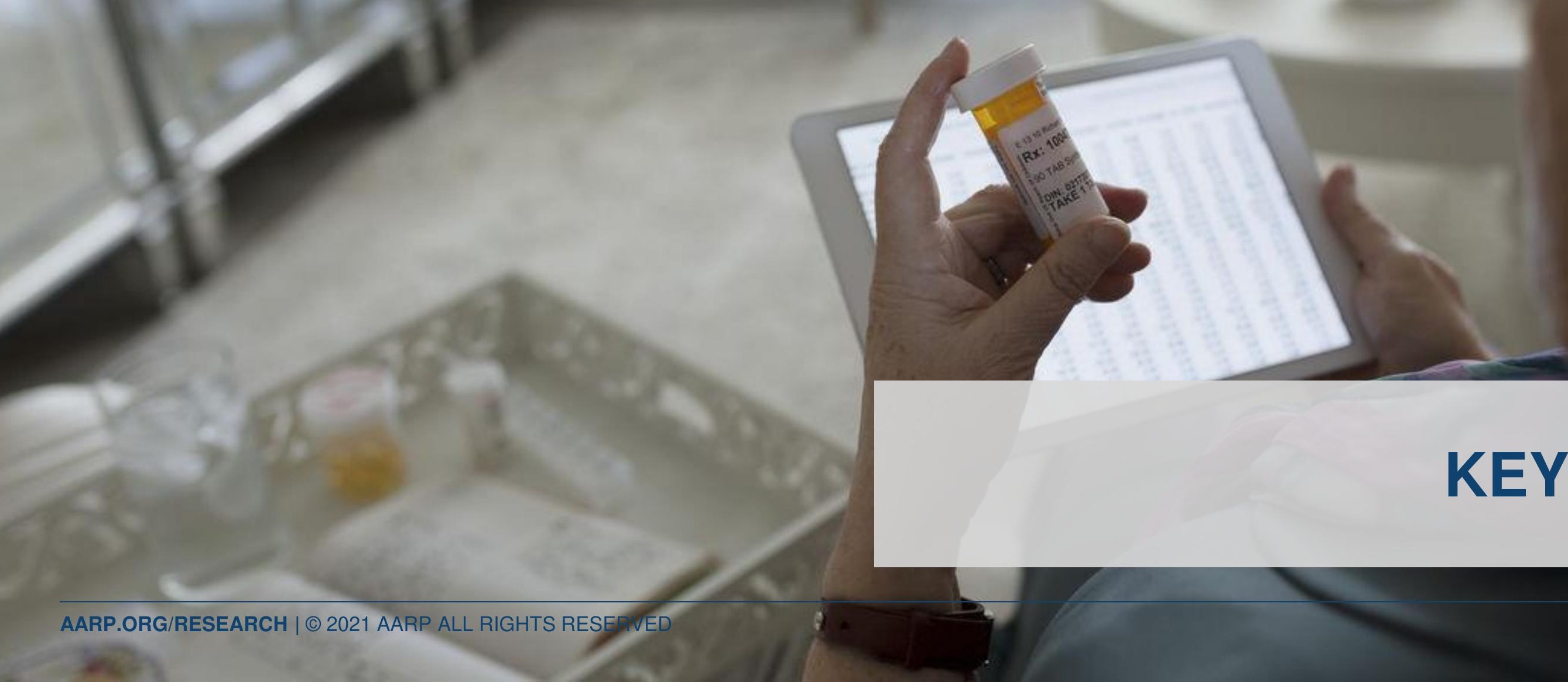

KEY FINDINGS 


\section{Key Findings}

Three-quarters of African American voters age 50+ take at least one prescription medication, and six in ten overall are at least somewhat concerned about affording prescription drugs for themselves or their family over the next few years. A full $18 \%$ said they would not fill a prescription that their doctor had given them. Cost is the top reason for people deciding not to fill a prescription provided by their doctor.

Nearly two-thirds believe that the prices of medications in the United States are higher than in other countries.

African American voters age 50+ overwhelmingly agree that this year, it is important for the president and Congress to agree on solutions to lower prescription drug prices. Successful government negotiations with drug companies for the COVID-19 vaccine has made many voters more likely to agree that the government should negotiate for lower prices for other drugs.

Support for various proposals to lower prescription drug prices is very high, with eight in ten agreeing that Medicare should be allowed to negotiate with drug companies for lower prices. Nearly three-quarters of African

American voters age $50+$ say they would view a member of Congress more favorably if they supported legislation to lower prescription drug prices. 


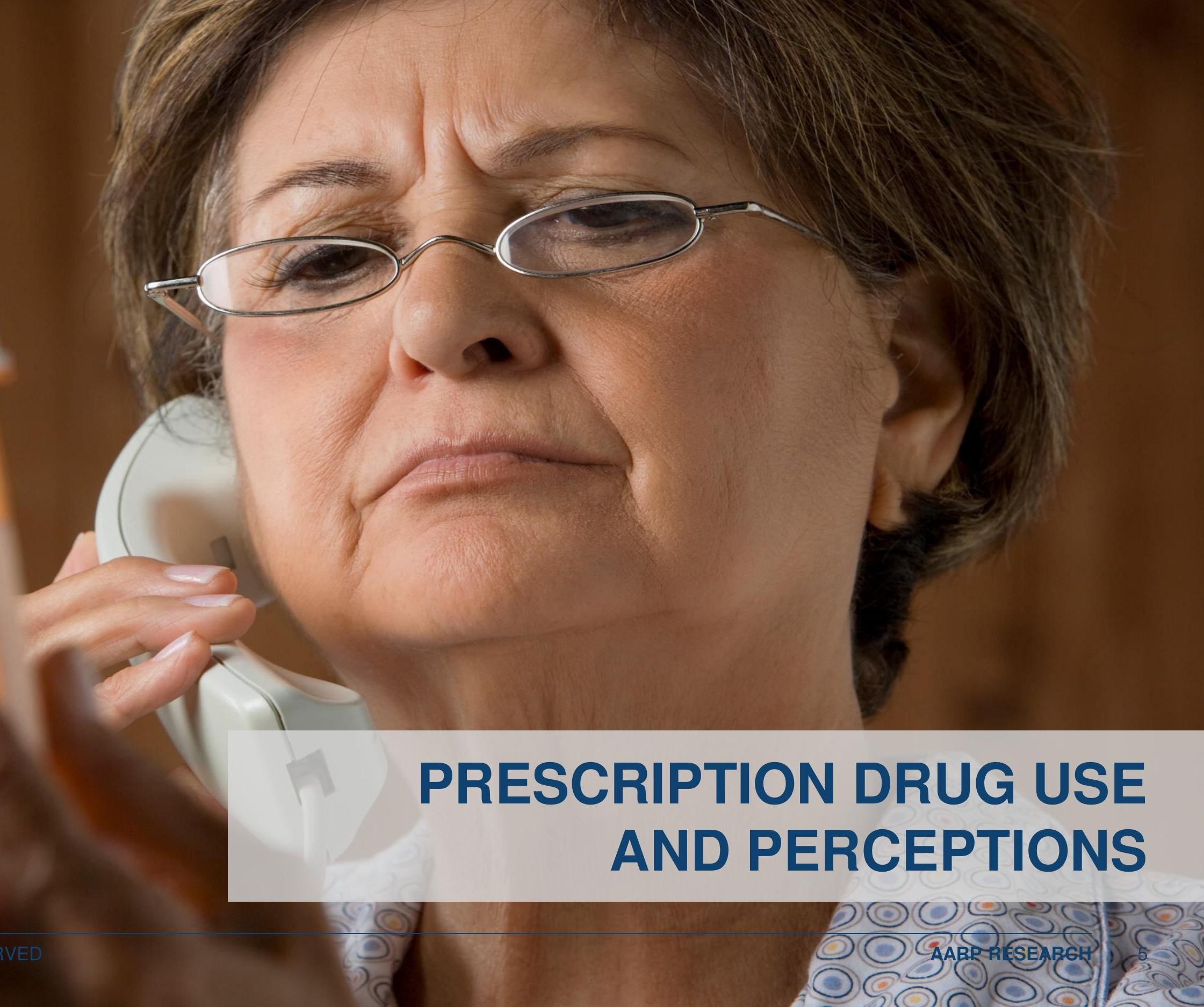




\section{Most registered African American voters 50-plus take prescriptions regularly; cost is top reason for not filling a prescription.}

Respondents ages 65 and older are roughly twenty-percentage points more likely than those ages 50-64 to report taking prescription drugs regularly ( $87 \%$ vs. $68 \%)$, but younger respondents are more likely to report not filling a prescription (23\% vs. $9 \%)$.

\section{Take prescription drugs regularly?}

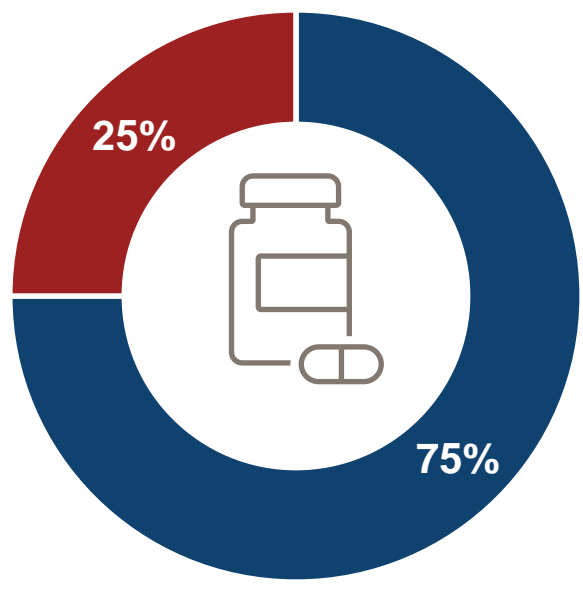

\section{Decided to not fill Rx?}

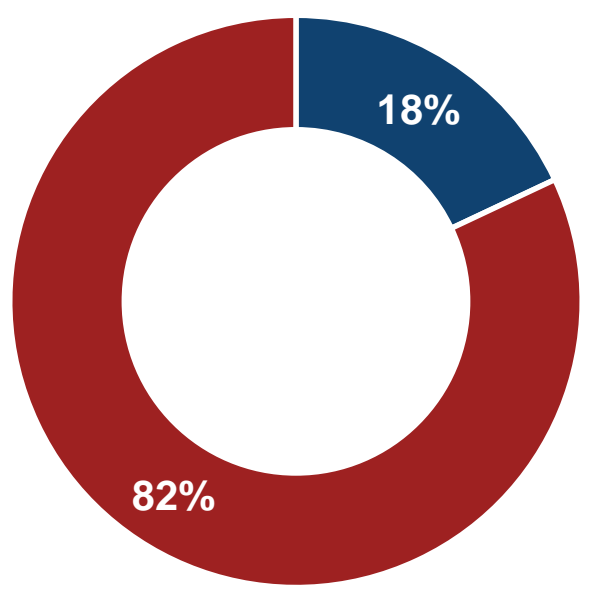

-Yes - No "Don't know/ref.

\section{Reasons for Not filling $\mathbf{R x}^{\star}$}

Cost of the drug

Didn't think you needed it

Side effects of drug

Don't like taking $\mathrm{Rx}$

Condition improved

Thought wouldn't help much

Used other treatments

Already taking too many

Something read / heard

Drug did not help in the past

Another doctor said not to

Confused about the drug

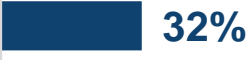

$30 \%$ $21 \%$ $19 \%$ $14 \%$ $14 \%$ $12 \%$ $9 \%$

$9 \%$

$8 \%$

$5 \%$

$5 \%$

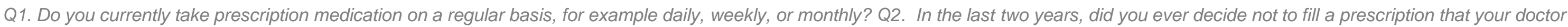

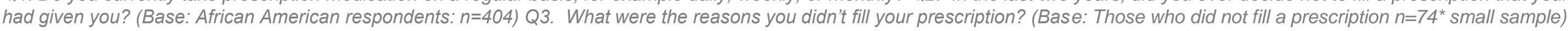




\section{High levels of concern around affordability of prescription drugs among African American voters age 50 and older.}

\section{Concern About Affordability of Prescriptions, by Age}

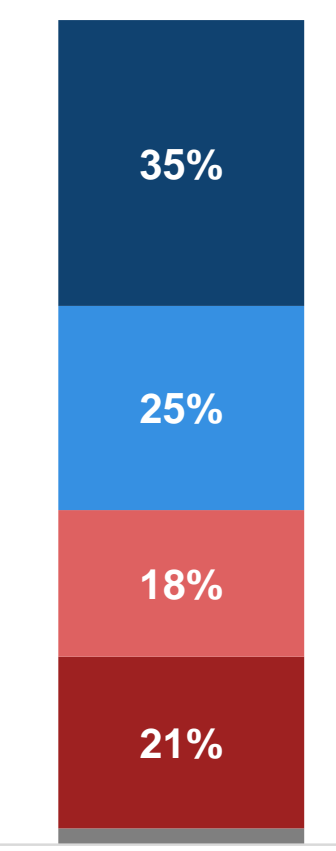

Total Black 50+ $(n=404)$

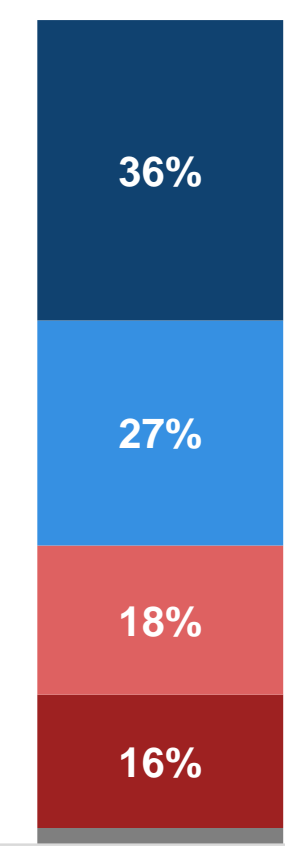

Age 50-64 $(\mathrm{n}=250)$

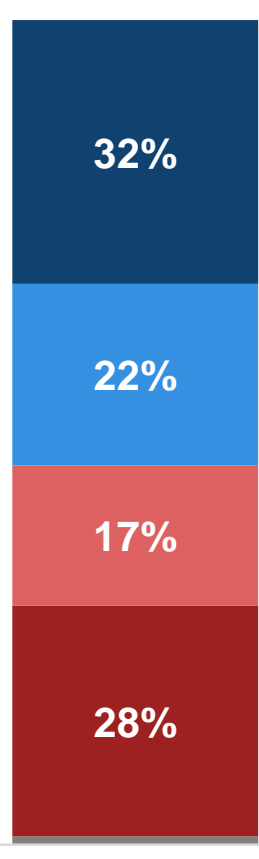

Age 65+

$(n=154)$
- Very concerned

- Somewhat concerned

$\backsim$ Not very concerned

- Not at all concerned

- Don't know/ refused

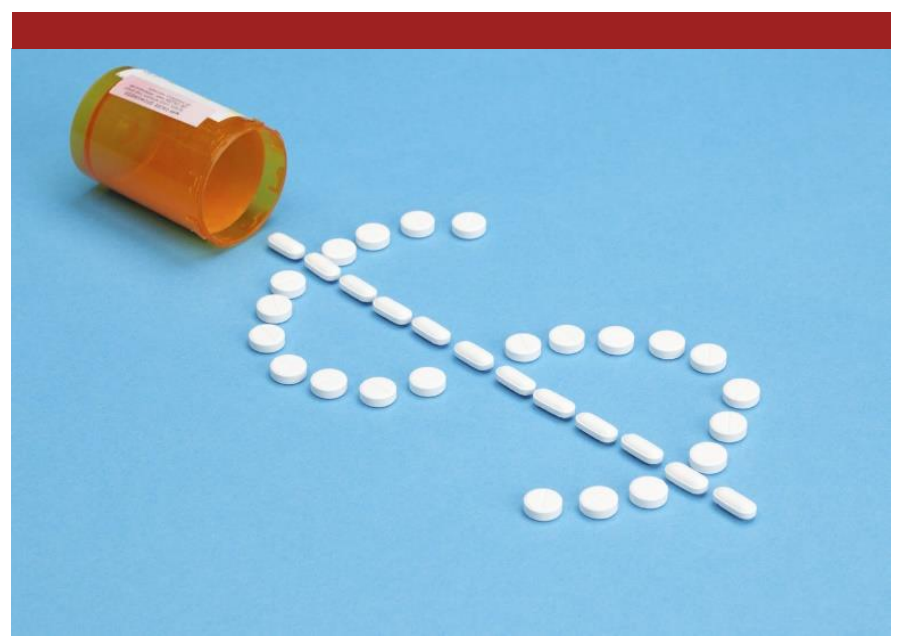

Q4. Thinking about the next few years, how concerned are you about being able to afford the cost of prescription medication you or a family member may need? (Base: African American respondents: $n=404$ ) 


\section{African American registered voters $50+$ believe U.S. consumers pay more for the same Rx drugs than do consumers in other countries.}

Perceived Prices of Drugs Paid in U.S. Compared to that Paid in Other Countries

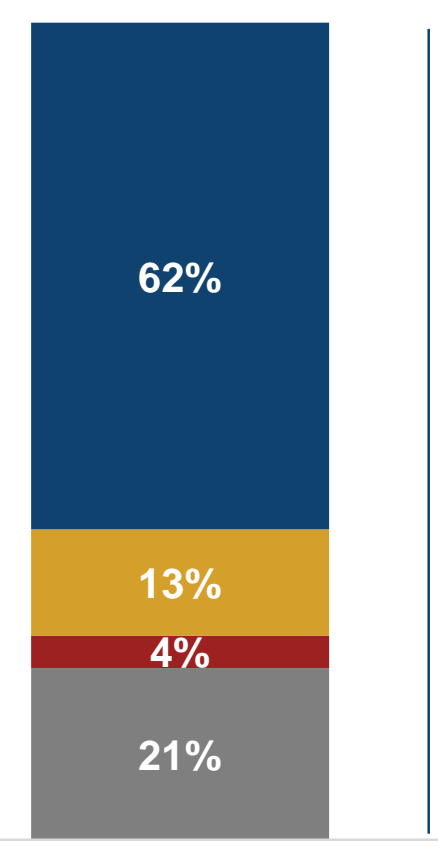

Total Black $50+\quad(n=404)$

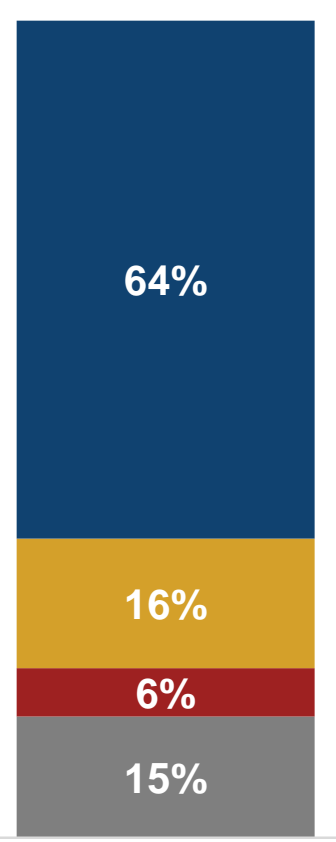

$50-64(n=250)$

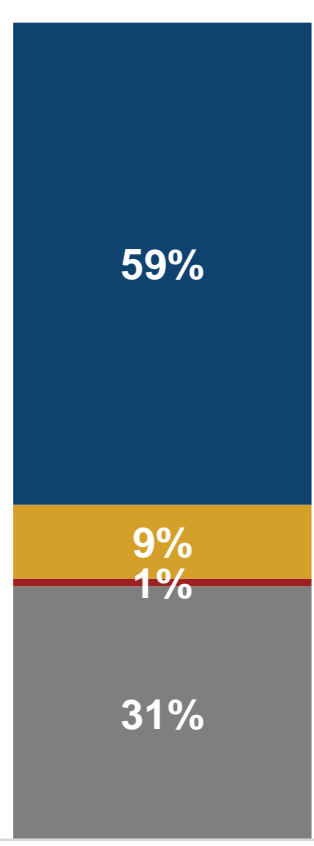

$65+(n=154)$
- More

About the same

- Less

- Don't know/ refused

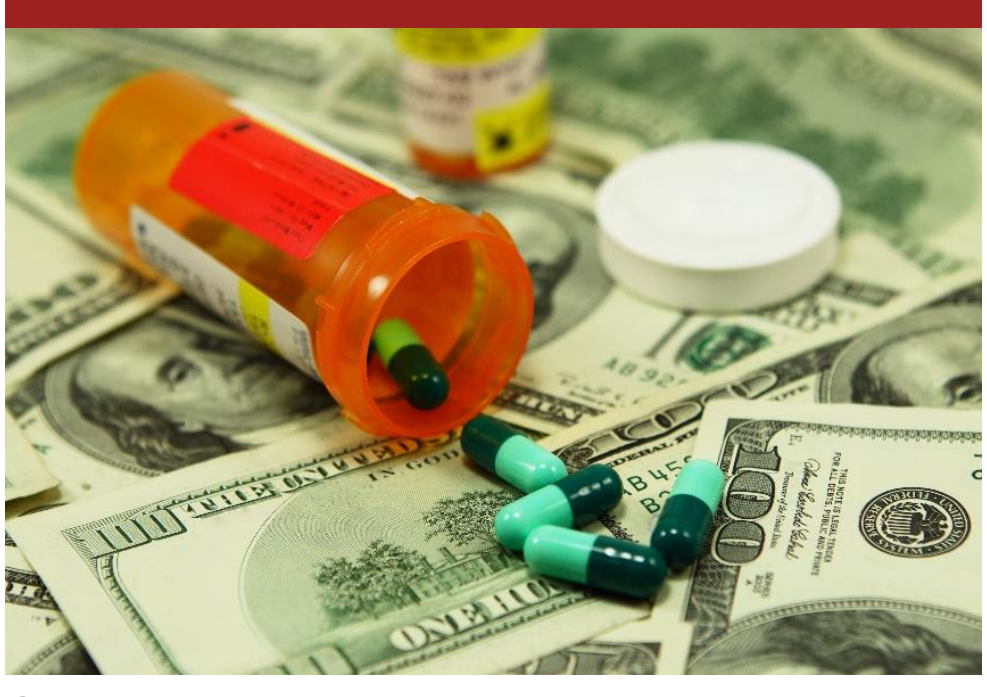

Q5. From what you may know, or had to guess, do

consumers in the United States pay more, the same or less

for the same drugs than consumers in other countries (such

as the United Kingdom, France, and Italy)?

(Base: African American respondents: $n=404$ ) 


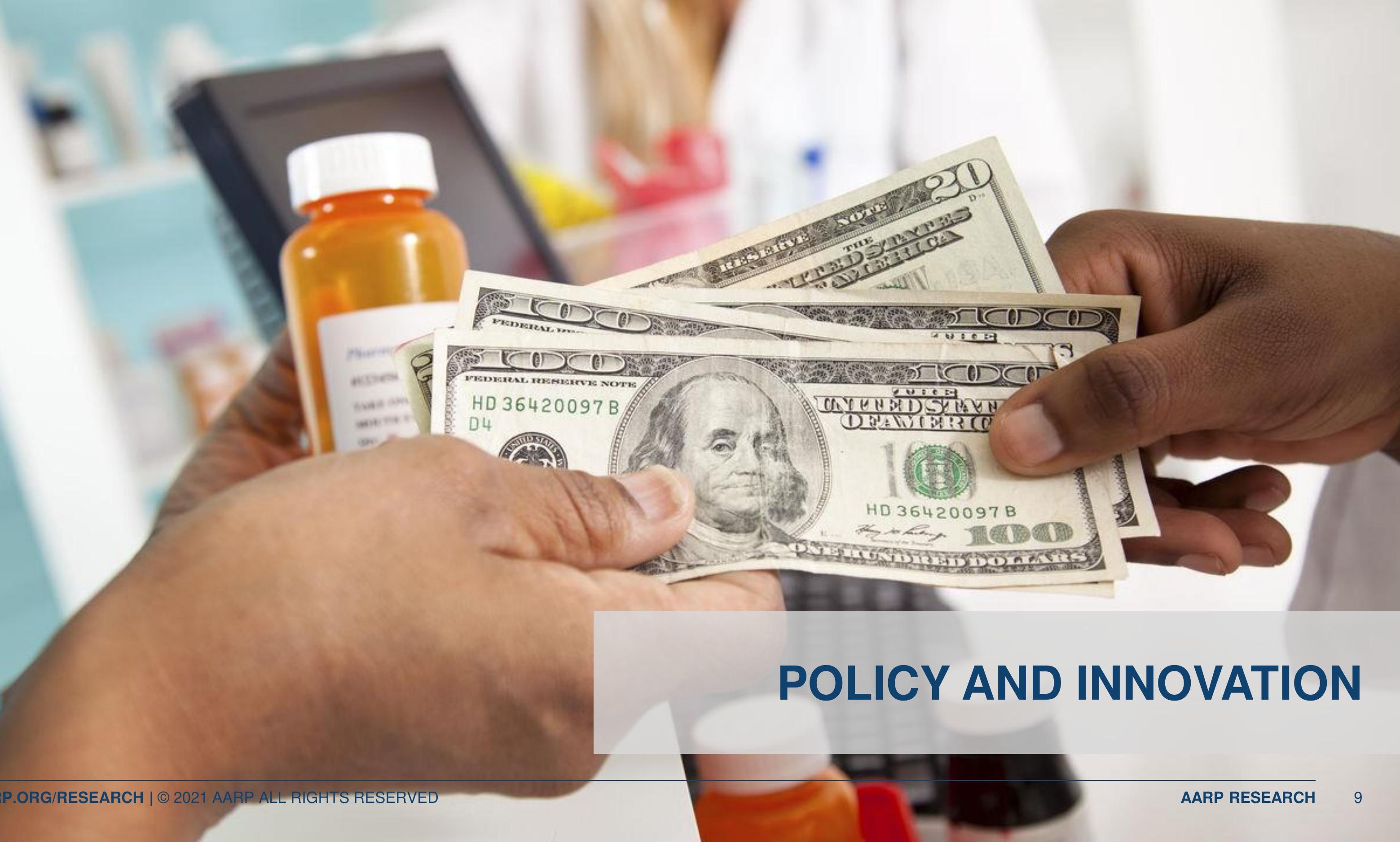




\section{African American voters 50+ note strong support for all five legislative proposals.}

\section{Support for Proposals To Lower Prescription Drug Prices (Percent 'Favor')}

\begin{tabular}{|c|c|}
\hline By Race/Ethnicity & $\begin{array}{l}\text { African } \\
\text { American }\end{array}$ \\
\hline & $n=404$ \\
\hline $\begin{array}{l}\text { Allow Medicare, the largest prescription drug purchaser in the U.S., to negotiate with drug } \\
\text { companies for lower prices }\end{array}$ & $82 \%$ \\
\hline Put a cap on the amount seniors have to pay out of pocket every year for their prescription drugs & $81 \%$ \\
\hline $\begin{array}{l}\text { Prevent drug companies from charging more for drugs in the United States than they do in other } \\
\text { countries }\end{array}$ & $76 \%$ \\
\hline $\begin{array}{l}\text { Close the loopholes that allow brand-name pharmaceutical companies to charge high prices for } \\
\text { new drugs that are simply copycats or minor improvements over existing drugs }\end{array}$ & $69 \%$ \\
\hline Penalize drug companies that raise their prices higher than inflation & $73 \%$ \\
\hline
\end{tabular}

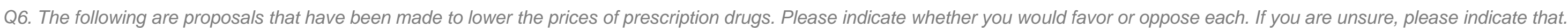




\section{Three in ten African American voters 50+ agree that allowing Medicare to negotiate for}

lower drug prices will make it harder to get lifesaving drugs to market.

Agreement that 'Innovation Will Suffer if Medicare Negotiates For Lower Prices'

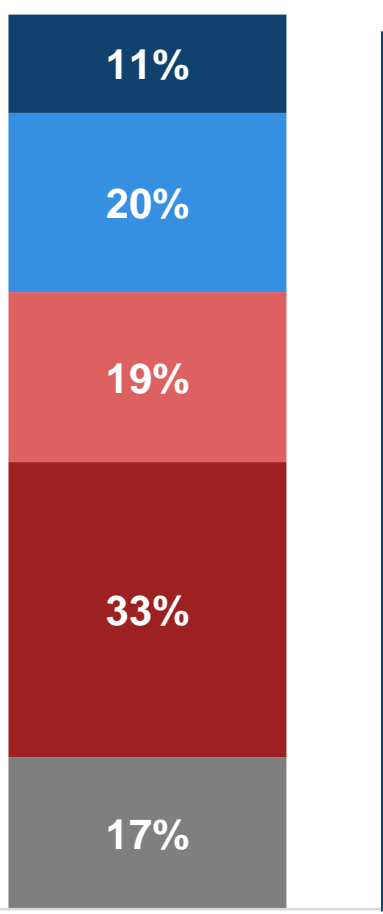

Total Black $50+(n=404)$

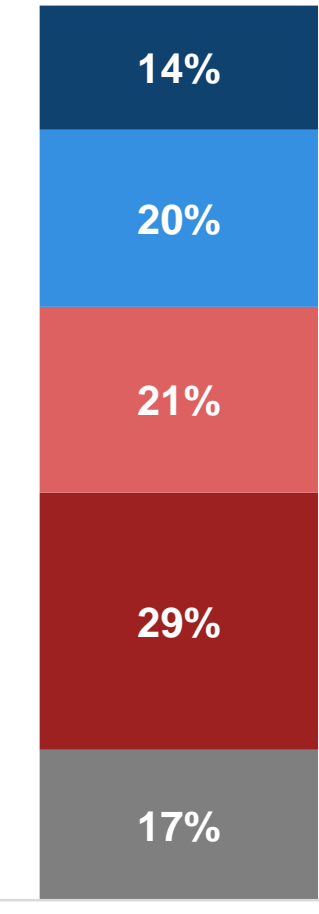

$50-64(n=250)$

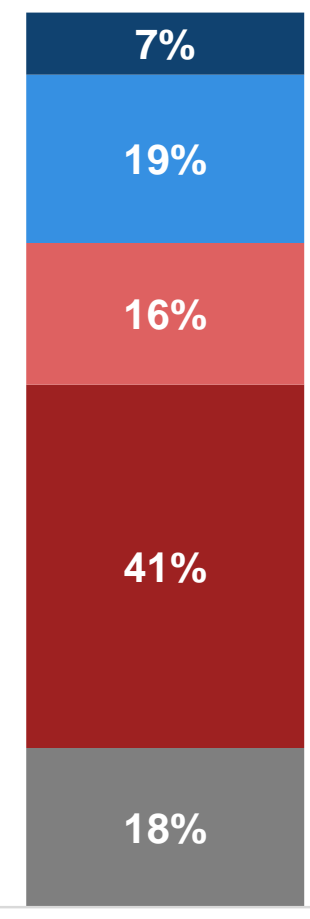

$65+(n=154)$
- Strongly agree

- Somewhat agree

- Somewhat disagree

- Strongly disagree

Don't know/ refused

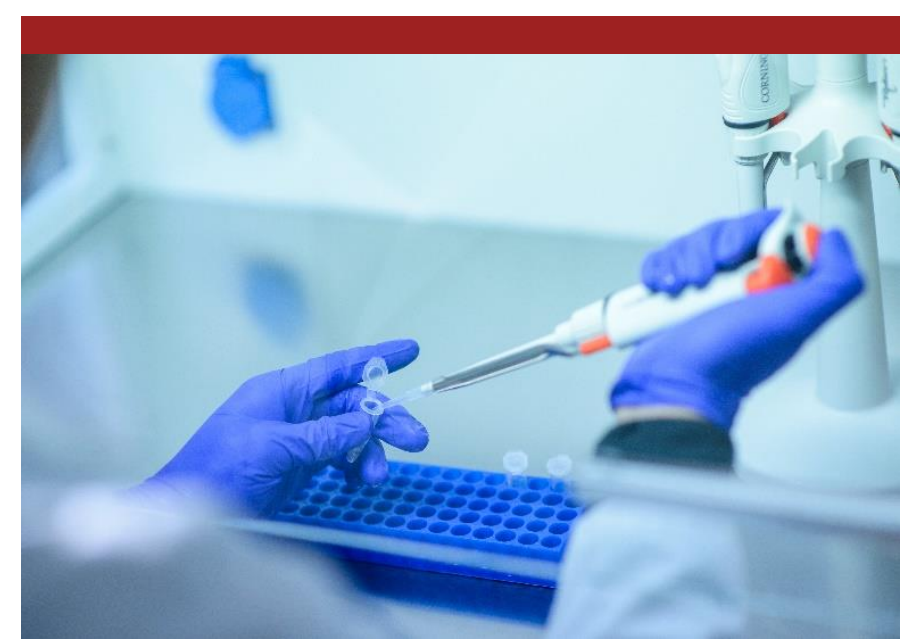

Q7. Some people say that if Congress passes legislation to allow Medicare to negotiate for lower prices, innovation will suffer, making it harder to get lifesaving drugs to market. Do you agree or disagree? (Base: African American respondents: $n=404$ ) 


\section{Majority agrees that drug prices can be lowered without affecting innovation.}

Agreement That 'Drug Prices Can Be Lowered Without Harming Innovation Of New Medicines'

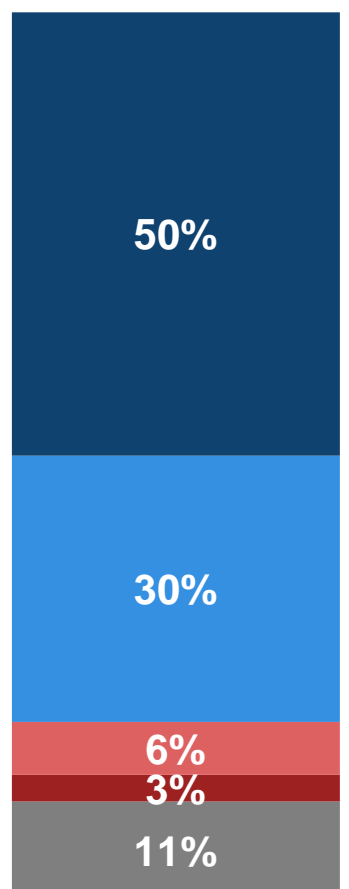

Total Black $50+\quad(n=404)$

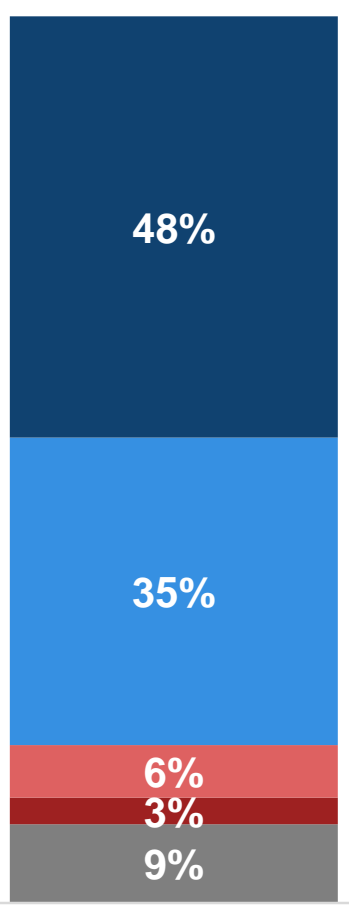

$50-64 \quad(n=250)$

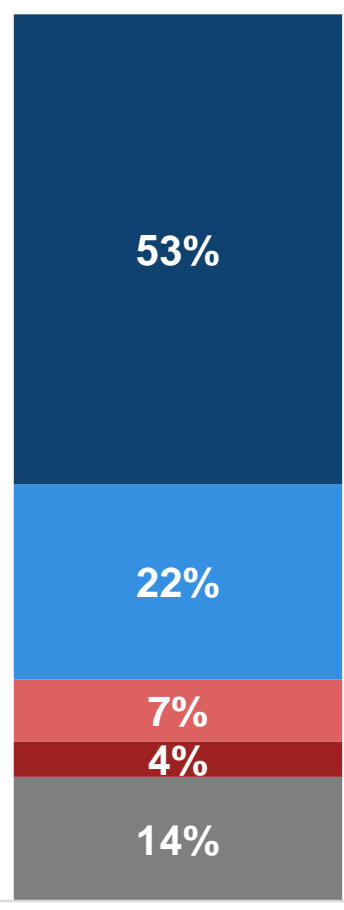

$65+(n=154)$
- Strongly agree

Somewhat agree

- Somewhat disagree

- Strongly disagree

Don't know/ refused

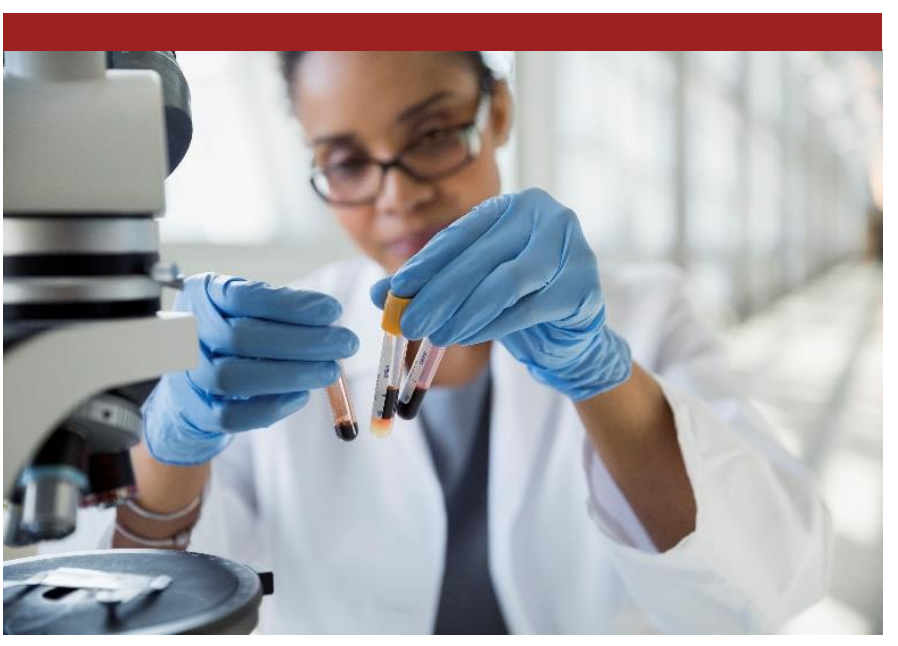

Q8. Some people say that drug prices in the U.S., which are 3 times higher than those in other countries, can be lowered without harming innovation of new medicines. Do you agree or disagree? (Base: African American respondents: $n=404$ ) 


\section{Consistent agreement that Congress needs to take action to lower Rx prices.}

Agreement is higher among Black voters 65-plus than among their younger counterparts ( $80 \%$ vs. $68 \%$ ).

Agreement That 'Congress Needs To Take Action To Lower Drug Prices'

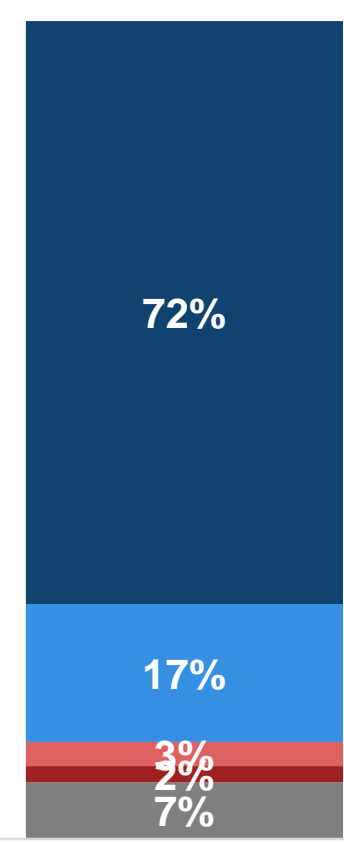

Total Black $50+(n=404)$

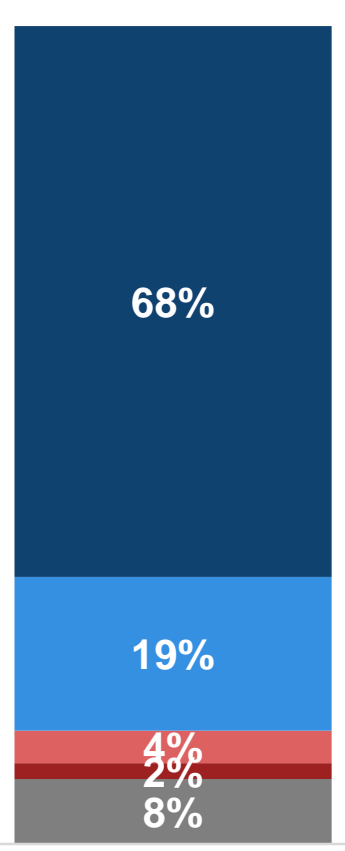

$50-64(n=250)$

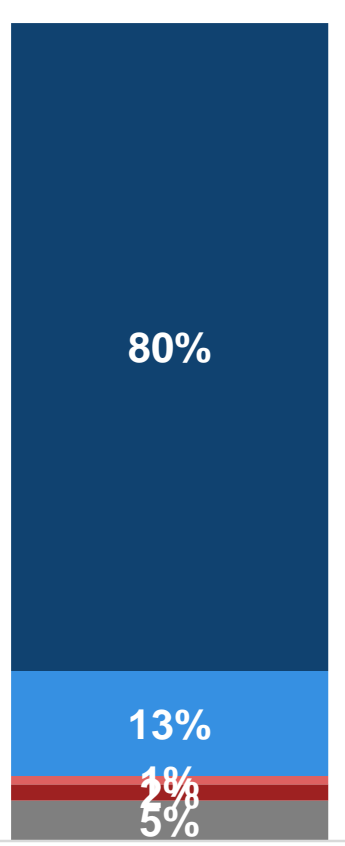

$65+(n=154)$
- Strongly agree

- Somewhat agree

- Somewhat disagree

- Strongly disagree

- Don't know/ refused

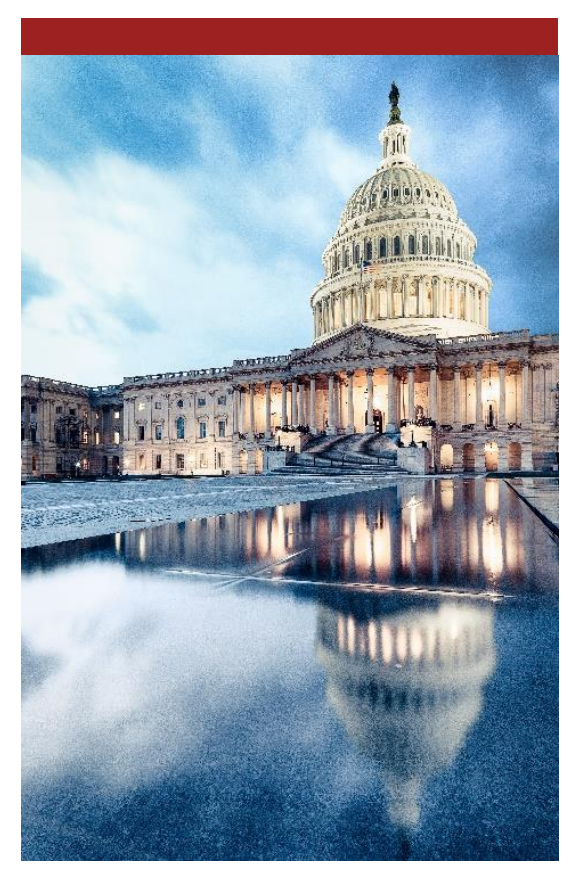

Q9. Some people say Congress needs to take action to lower drug prices because some people can't afford to buy medicine and pay for other necessities. Do you agree or disagree? (Base: African American respondents: $n=404$ ) 
Majorities say recent successful COVID-19 vaccine negotiations made them more likely to agree that the government should negotiate for lower prices for other drugs.

Impact Of Successful COVID-19 Vaccine Negotiations On Agreement That Government Should Negotiate Price For Other Drugs

Total Black

$50+(n=404)$

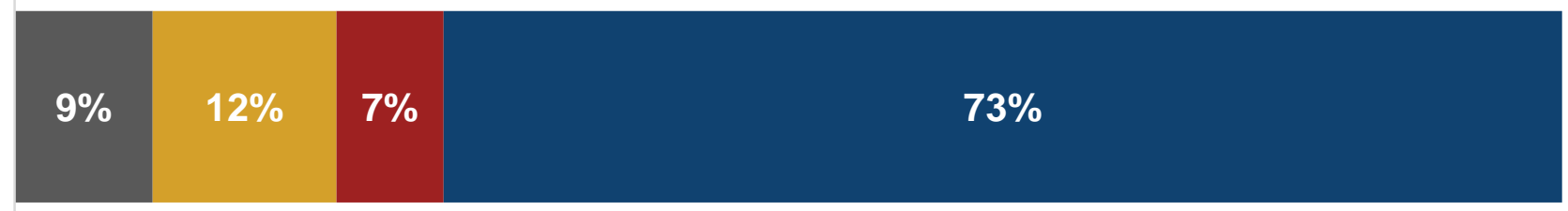

$50-64(n=250)$

$9 \%$

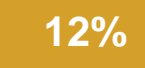

$8 \%$

$70 \%$

$65+(n=154)$

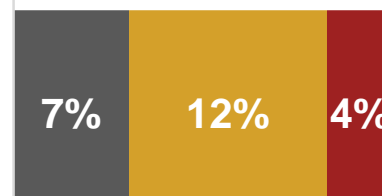

\section{$77 \%$}

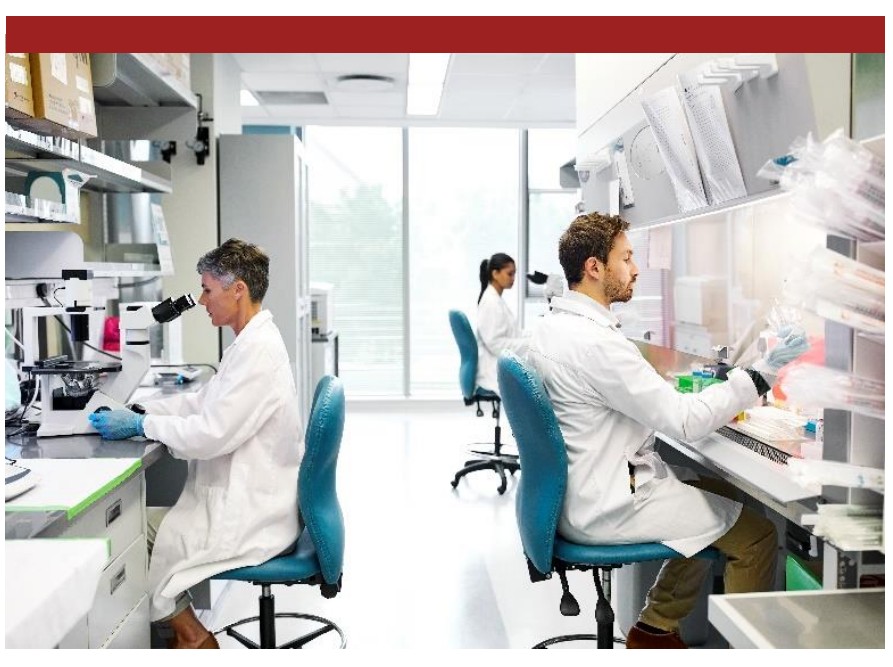

Q10. The U.S. government just successfully negotiated with drug companies on the price for the COVID-19

vaccine. Does that make you more or less likely to

agree that the government should negotiate for lower drug prices for people on Medicare?

(Base: African American respondents: $n=404$ ) 


\section{Eight in ten black voters believe that Presidential/Congressional}

agreement on solutions to lower drug prices this year is very important.

Importance Of Government Agreeing On Solutions

To Lower Drug Prices This Year

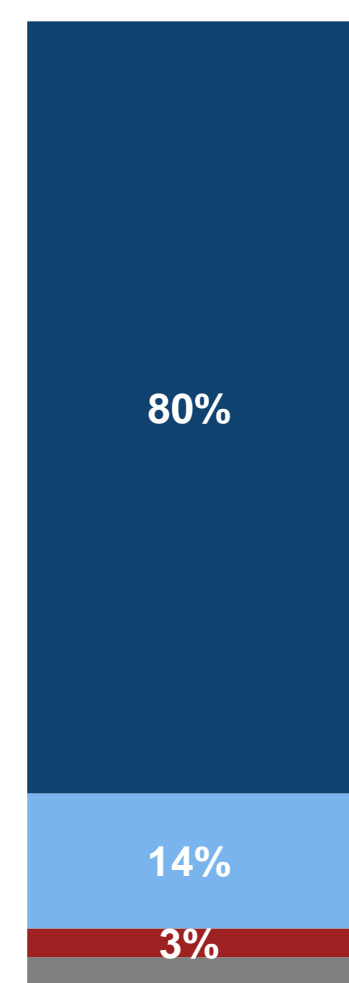

Total Black $50+(n=404)$

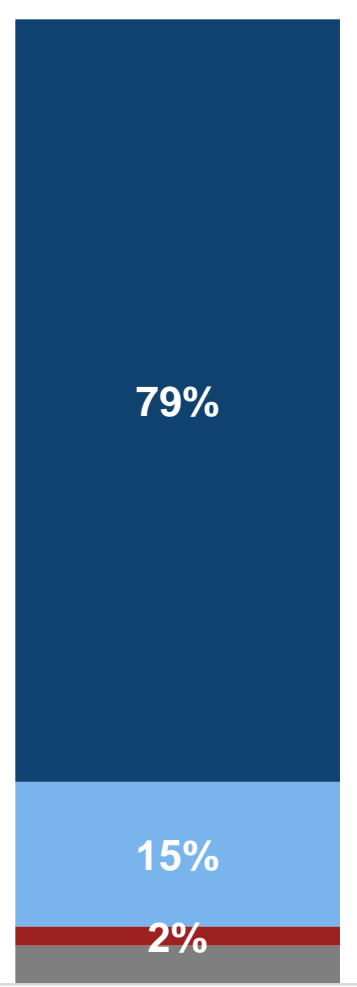

$50-64(n=250)$

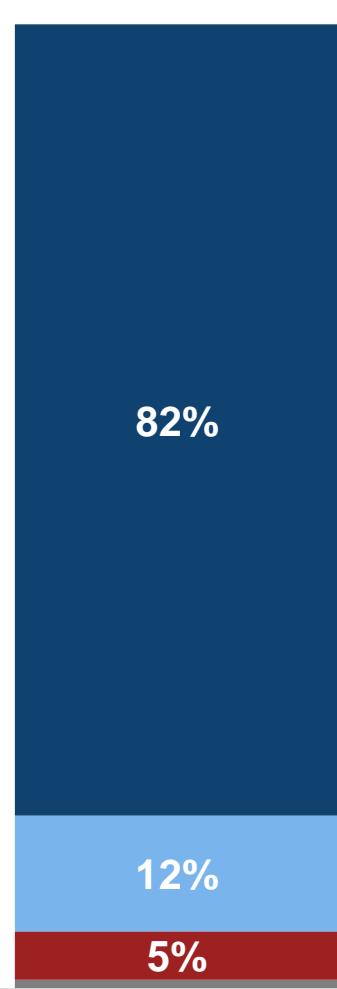

$65+(n=154)$
- Very important

- Somewhat important

- Not very or not at all important

- Don't know/ refused

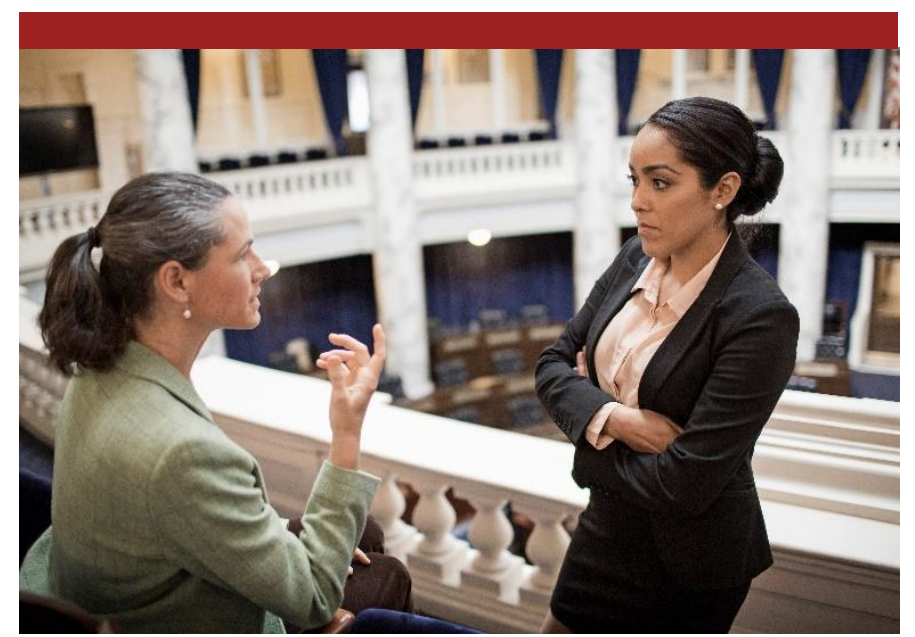

Q11. How important is it for the president and Congress to agree on solutions to lower prescription drug prices this year? (Base: African American respondents: $n=404$ ) 


\section{Black voters 50-plus would be more favorable to a member of Congress who supports legislation to lower drug prices.}

Favorable to Members of Congress Who Support

Legislation To Lower Drug Prices

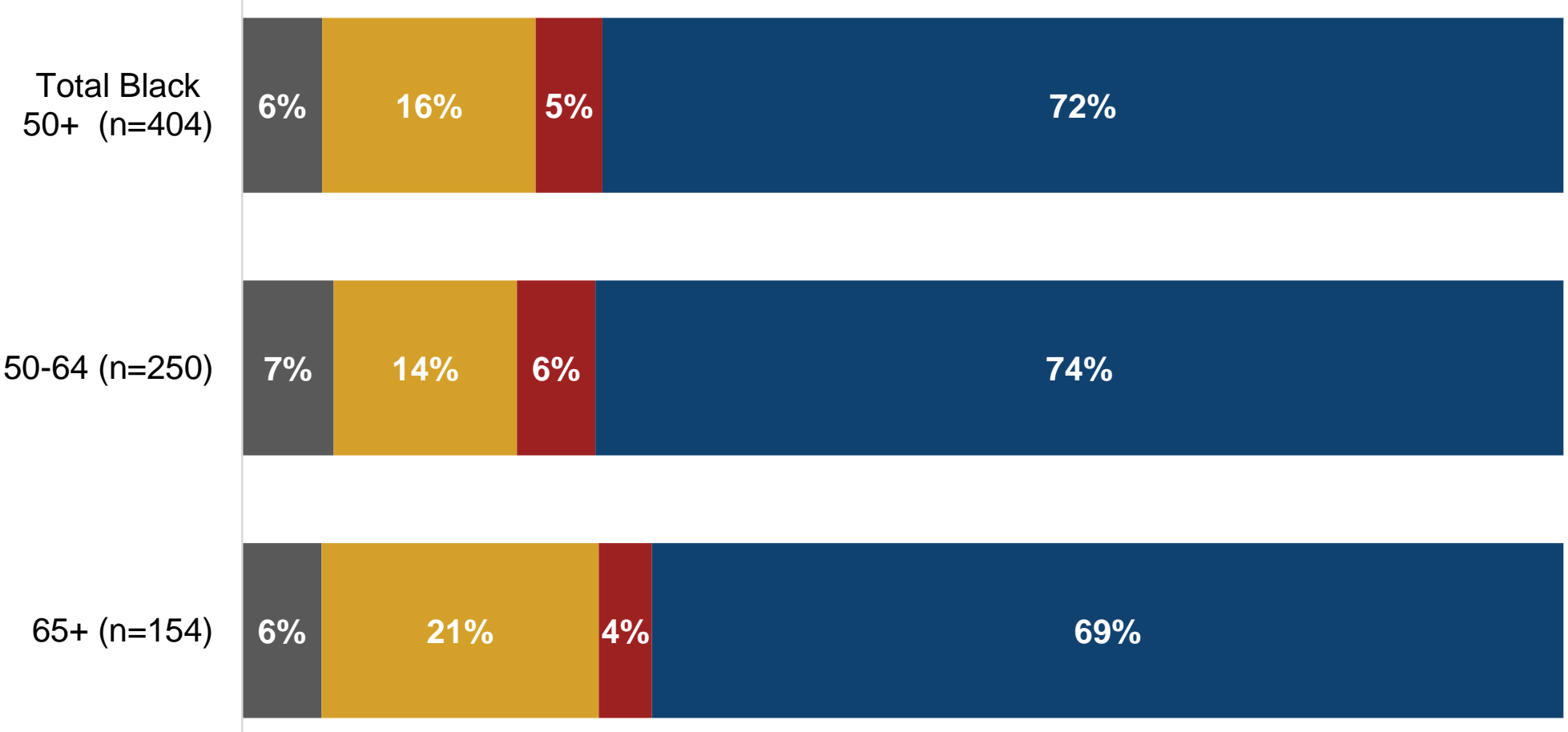

Don't know/ refused

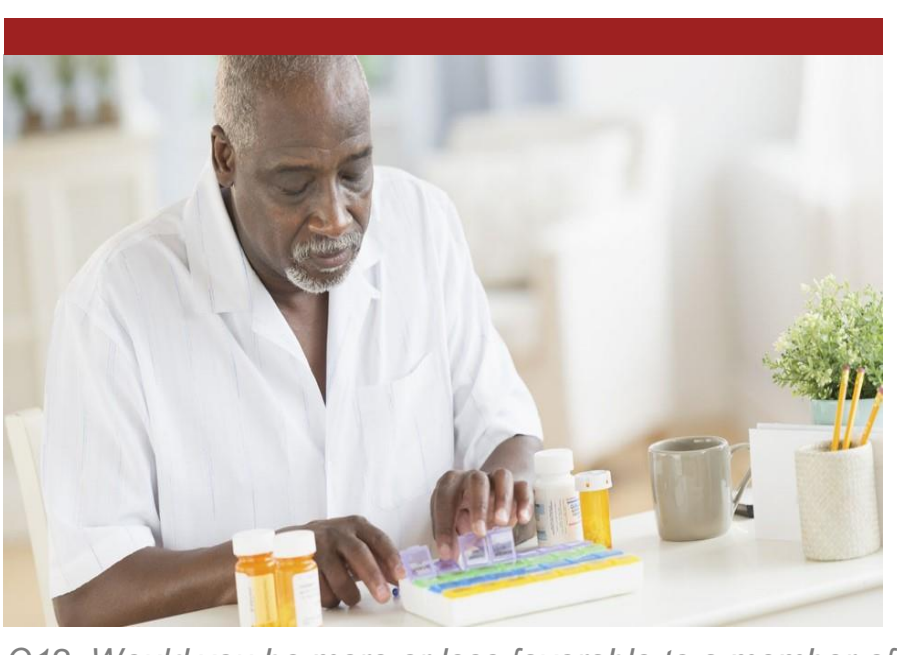

Q12. Would you be more or less favorable to a member of Congress that supported legislation to lower prescription

drug prices, or would it have no effect on your opinion?

(Base: African American respondents: $n=404$ ) 


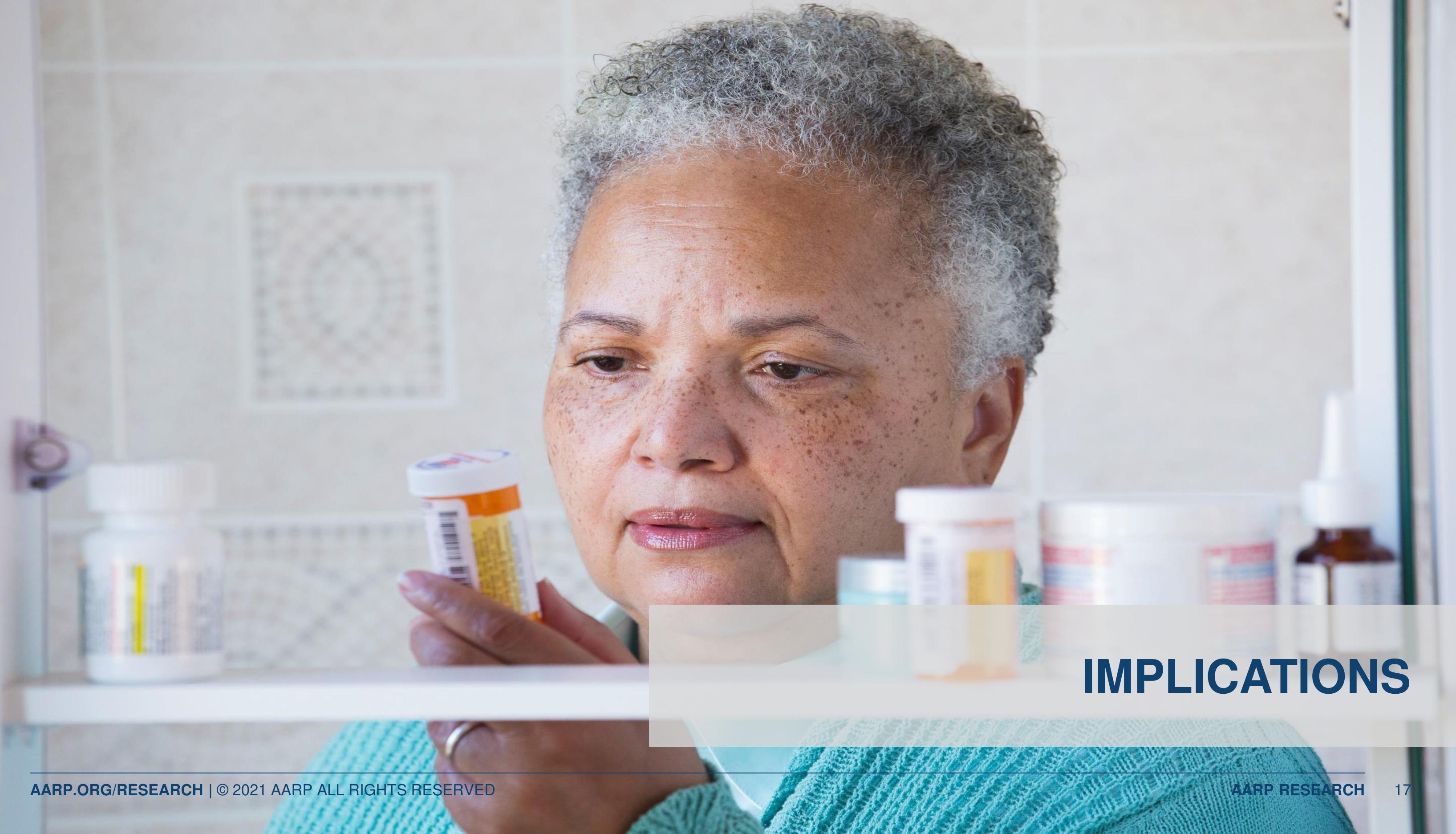




\section{Implications}

High prescription drug prices affect most U.S. voters age 50 and older, many of whom take medications regularly or are concerned about affording prescription drugs for their family over the next few years.

Voters are united in agreement that Congress should take action to lower prescription drug prices, with an overwhelming number of voters feeling that it is important for the president and Congress to agree on solutions this year.

The majority agree that drug prices can be reduced without harming innovation, and many voters would be more likely to favor a member of Congress who supported legislation to lower prescription drug prices.

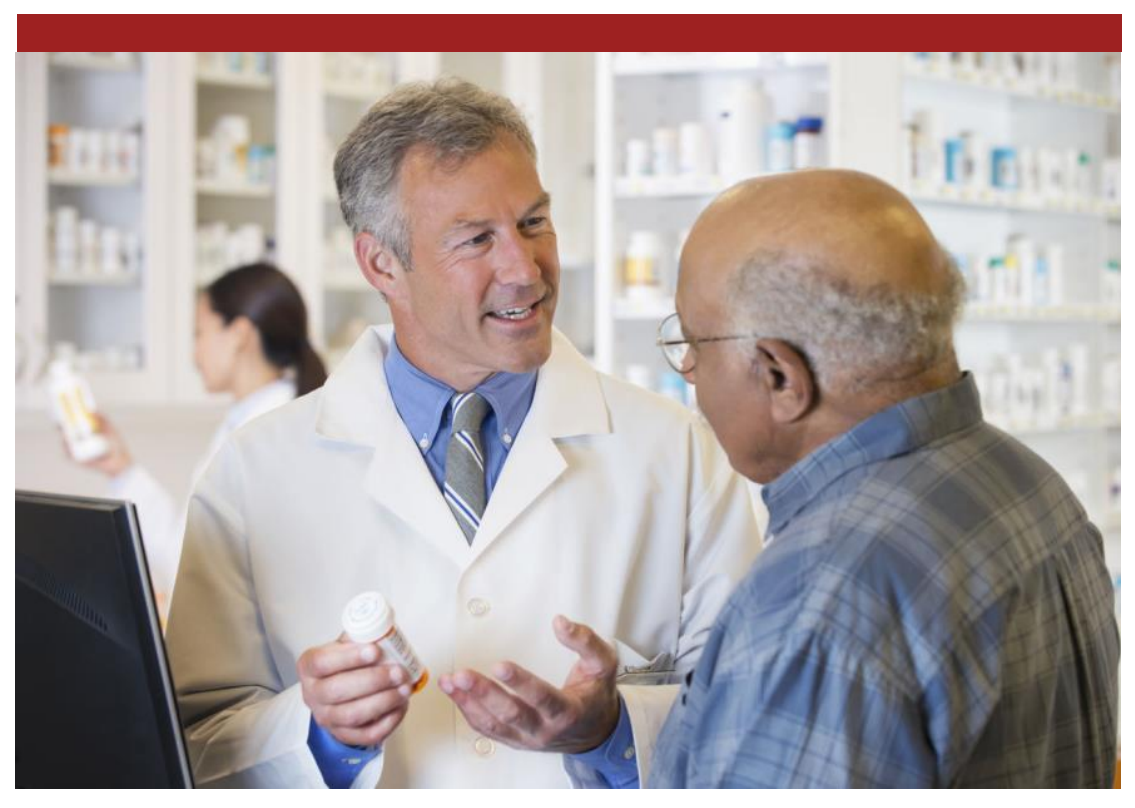

Support is high for a variety of proposals that would aim to lower prescription drug prices, particularly those allowing Medicare to negotiate with pharmaceutical companies to lower drug prices for Medicare recipients. 


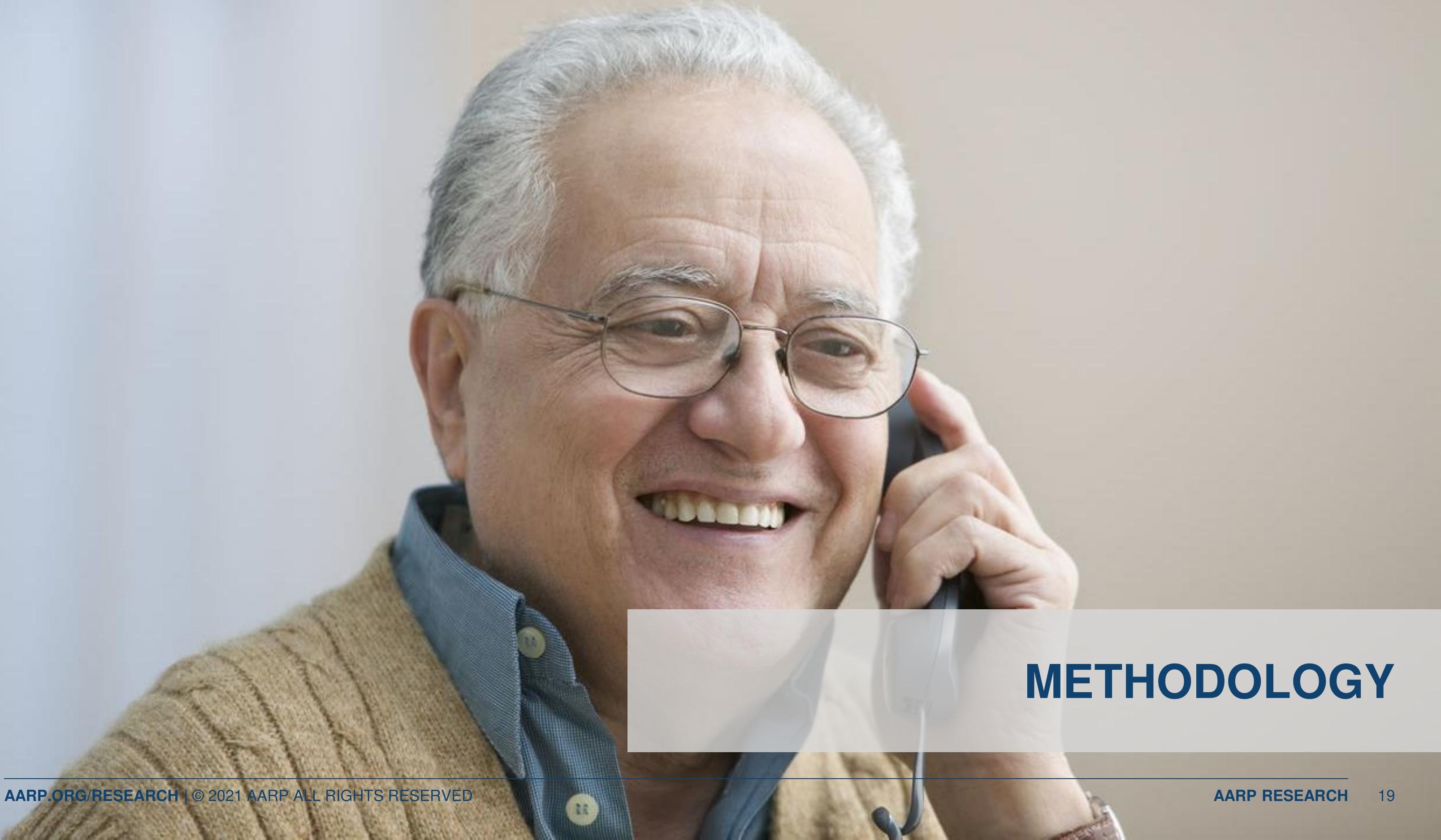




\section{Methodology}

- Objectives: To explore the use of prescription drugs and concerns relating to prescription drugs among United States voters age 50 and older

- Methodology: Phone, nationally representative survey

- Sample: U.S. registered voters age 50 and older (60\% via landline telephones and $40 \%$ via cell phones); $n=1,605$ total sample

- Base sample: $n=1,000$

- Oversamples: $n=404$ African Americans (focus of this report); $\mathrm{n}=414$ Hispanic/Latinos 50+

- Interviewing Dates: June 1, 2021 - June 13, 2021

- Language: Interviews conducted in English and Spanish

- Weighting: Data weighted by age, gender, race/ethnicity, and education according to 2019 5-year U.S. Census Bureau American Community Survey (ACS) estimates

- Questionnaire length: 9.6 minutes (average)

- Confidence Intervals: $\pm 3.1 \%$

Note: Some percentages may not equal $100 \%$ due to rounding or the use of multiple response question formats. 


\section{About AARP}

AARP is the nation's largest nonprofit, nonpartisan organization dedicated to empowering Americans 50 and older to choose how they live as they age. With nearly 38 million members and offices in every state, the District of Columbia, Puerto Rico, and the U.S. Virgin Islands, AARP works to strengthen communities and advocate for what matters most to families with a focus on health security, financial stability and personal fulfillment. AARP also works for individuals in the marketplace by sparking new solutions and allowing carefully chosen, high-quality products and services to carry the AARP name. As a trusted source for news and information, AARP produces the nation's largest circulation publications, AARP The Magazine and AARP Bulletin. To learn more, visit www.aarp.org or follow @AARP and @AARPadvocates on social media.

\section{About ANR Market Research Consultants}

ANR is a full-service market research firm founded in 1978. It has a full-time staff of twelve people and a part-time staff of thirty-five. As a Virginia SWaM-certified small business, ANR is managed by executives age $50+$ and also employs multiple professional staff age 50+. Its corporate offices, located in Richmond, Virginia, include a state-of-the-art focus group facility. ANR specializes in business and consumer research to determine attitudes and opinions, advertising effectiveness, organization image and awareness, market positioning and new product development. Its clients span a variety of industries, including state and federal government, health care, communications, finance, manufacturing, retail, travel, tourism, real estate development, and education. For more information, visit www.anr.com. 
